\title{
Bayesian Estimation of Resistance Factor for Bored Piles Based on Load Test Database
}

\author{
Zhijun Xu (i), Ranran Zhang, Liang Fan, Xing Han, Fang Yuan, and Mingfang Du \\ College of Civil Engineering, Henan University of Technology, Zhengzhou 450001, China \\ Correspondence should be addressed to Zhijun Xu; zj.xu_hust@qq.com
}

Received 19 January 2020; Revised 31 May 2020; Accepted 3 September 2020; Published 15 September 2020

Academic Editor: Chongchong Qi

Copyright (c) 2020 Zhijun Xu et al. This is an open access article distributed under the Creative Commons Attribution License, which permits unrestricted use, distribution, and reproduction in any medium, provided the original work is properly cited.

\begin{abstract}
The quality of in situ data is key to calculating resistance factor of bored piles. However, it is difficult to summarize accuracy data due to various uncertainties in engineering. This paper employs the Bayesian method and mathematical statistics theory to put forward an estimation method for updating in situ data. A testing database (33 tests in noncohesive soils and 53 tests in cohesive soils) of bored piles is summarized. The model factor of bored piles is quantified as the ratio of the measured capacity to the calculated capacity. The proposed method is used to classify summarized data into three categories, which are "good data," "general data," and "bad data." The "bad data" are discarded because of bad contribution to calculation, and Bayesian theory is incorporated into updating the model factor statistics. Three methods are used to calculate the reliability index and resistance factor of bored piles, and the results show that the reliability index and resistance factor are sensitive to the quality of data. Finally, the available values of resistance factors are proposed based on resistance factor design for bridge design specification, which can offer references to revision relevant specifications. The proposed method can be used to update other geotechnical data.
\end{abstract}

\section{Introduction}

Bored piles, especially large-diameter piles, are commonly employed to support high-rise buildings and bridges in China and other countries because of their ability to sustain large load [1-5]. The safety of bored pile foundation is significantly important. Due to various uncertainties, the design parameters should have random variances. However, design parameters are described as constants by allowable stress design (ASD) philosophy, which is unreasonable and unscientific. To overcome the deficiencies, load resistance factor design (LRFD) method is mandated by American Association of State Highway and Transportation Officials [6]. Therefore, resistance factor calculation of bored piles is of engineering significance.

The resistance factor is calculated incorporating in reliability analysis methods based on pile load test data $[7,8]$. Enough-accuracy in situ data are necessary to calculate resistance factor of bored piles. However, it is difficult to collect accuracy in situ data to calculate reliability index and resistance factor because of various uncertainties, for example, parameter uncertainty, calculation model uncertainty, testing random error, and systematic error. A large number of investigations are carried out to calibrate resistance factor of driven piles [7-16], and significant achievements have been developed. However, few investigations about resistance factor of bored piles have been reported.

Parameter uncertainty and model uncertainty are two troubles for pile foundation designers. Numerous investigations are conducted to study parameter uncertainty, which shows that parameter uncertainty contains random error of monitor, system error, statistical uncertainty, and so on. Model uncertainty is mainly caused by simplified calculation model. European design specification of geotechnical engineering (EN997-1) clearly suggests that a model revised factor should be incorporated when the pile capacity is calculated using the simplification model [17]. However, this specification does not specify revised factor values and only suggests that different countries should adopt different values. Jones et al. [18], Kulhawy and Trutmann [19], Lacsse and Nadim [20], Meyerhof [21], and Phoon and Kulhawy 
$[22,23]$ study model uncertainty based on lots of in situ data of pile capacity, which shows that enough-accuracy data are necessary to solve model uncertainty problem. However, it is difficult to get enough-accuracy data due to various uncertainties. In addition, the quality of collected data is not all perfect, and some of them are considered as "bad data" or "data outliers." It is necessary that data optimization is incorporated into calculating resistance factor of bored piles.

This paper puts forward a Bayesian estimation method to update the in situ data of bored piles, and three reliability index calculation methods are incorporated into calculating the reliability index of pile capacity using the processing data. Then American LRFD for Bridge Design Specification is used to estimate the resistance factor of bored piles.

\section{Bayesian Optimization Method}

Bayesian principle is a tool to update the probability distribution using new information. Assuming that the prior distribution of a random variable $(X)$ is $f_{X}^{\prime}(X)$, its posterior distribution can be written as [24]

$$
f_{X}^{\prime \prime}(X)=K \cdot L(X) \cdot f_{X}^{\prime}(X)
$$

where $f_{X}^{\prime \prime}(X)$ is posterior distribution of $X ; K$ is a normalization constant; and $L(X)$ is likelihood function. Normal distribution and log-normal distribution are frequently employed to fit probability distribution of pile capacity [25].

Assume that $n$ values of $X$ are collected from engineering, which are described as $X=\left(X_{1}, X_{2}, \ldots, X_{n}\right)$. The mean $\left(\mu_{p}\right)$ and standard variance $\left(\sigma_{p}\right)$ are

$$
\begin{aligned}
& \mu_{P}=\frac{1}{n} \sum_{i=1}^{n} X_{i}, \\
& \sigma_{p}=\sqrt{\frac{1}{n-1} \sum_{i=1}^{n}\left(x_{i}-\mu_{x}\right)^{2} .}
\end{aligned}
$$

Assume that $\mu_{K}$ and $\sigma_{K}$ are considered as the mean and standard variance of likelihood function. If $X$ obeys normal distribution, the posterior mean $\left(\mu_{U}\right)$ and variance $\left(\sigma_{U}\right)$ are

$$
\begin{aligned}
& \mu_{U}=\frac{\mu_{P} \sigma_{K}+\mu_{K} \sigma_{P}^{2}}{\sigma_{P}^{2}+\sigma_{K}^{2}}, \\
& \sigma_{U}^{2}=\frac{\sigma_{P}^{2} \sigma_{K}^{2}}{\sigma_{p}^{2}+\sigma_{K}^{2}} .
\end{aligned}
$$

If $X$ obeys log-normal distribution, it can be translated into normal random variable through dealing $X$ with natural logarithm, which is described as $\ln X$. The mean $\left(\mu_{\ln X}\right)$ and standard variance $\left(\sigma_{\ln X}\right)$ of $\ln X$ are

$$
\begin{gathered}
\mu_{\ln X}=\exp \left(\mu_{U}+0.5 \sigma_{U}^{2}\right), \\
\sigma_{\ln X}^{2}=\mu_{\ln X}\left[\exp \left(\sigma_{U}^{2}\right)-1\right] .
\end{gathered}
$$

The model factor is frequently represented as the ratio of the measured capacity to calculated capacity $[1,7,8]$ :

$$
\lambda=\frac{Q_{m}}{Q_{p}},
$$

where $\lambda$ is model factor of pile capacity; $Q_{m}$ is the measured pile capacity; and $Q_{p}$ is the calculated pile capacity. Numerous investigations show that model factor is a random variable and obeys log-normal distribution $[1,2,7,10,13,14]$.

To improve accuracy of collected data from engineering, this paper employs the biased factor of $\lambda$, which is shown in the following equation [26]:

$$
\zeta_{i}=\frac{\left|\lambda_{i}-\lambda_{R}\right|}{\lambda_{R}}, \quad 1 \leq i \leq n,
$$

where $\lambda_{i}$ is the $i$ th model factor; $\zeta_{i}$ is $i$ th biased factor of $\lambda$; and $\lambda_{R}$ is the mean of $\lambda$.

Based on equation (8), the data are classified as follows [26]:

(1) If $\zeta_{i}<0.25$, the data are defined as "good data" because it is near to the fact data.

(2) If $0.25 \leq \zeta_{i}<0.5$, the data are defined as "general data."

(3) If $\zeta_{i} \geq 0.5$, the data are defined as "bad data." "Bad data" are identified as extreme values, which should be discarded.

"Good data" are considered to be more reliable and should be treated as the prior information in estimation of the population statistics. However, the sample size of the "good data" is not sufficient to represent the total. This paper employs Bayesian updating technique to evaluate the probability characteristics of the resistance bias factor for bored piles. The "general data" are treated as prior information, and the "good data" are treated as likelihood information. Then, the updating model factor statistics can be obtained using equations (3)-(6).

\section{Resistance Factor Estimation}

This paper summarizes various bored pile capacity data shown in Tables 1 and 2 [1]. The data are divided into two groups, which are the data in noncohesive soil (D-NC) and the data in cohesive soil (D-C).

Dithinde et al. [1] use load-displacement curves (shown in Figure 1) to improve the quality of collected data. The characteristic of Case Numbers 25 curve is far away from other curves; it falsely needs to be discarded. In addition, Dithinde et al. [1] employ Box-Plots Method to detect that Case Number 24 and Case Number 26 are outliers. Therefore, Case Numbers 24, 25, and 26 should be discarded. Figure 2 shows the scatter diagram of the remaining data, which indicates that there are no data deviating markedly from other data. However, it does not mean that the remaining data are absolutely reliable. This paper will use the proposed method to update remaining data. 
TABLE 1: Load testing data of pile capacity in noncohesive soil.

\begin{tabular}{|c|c|c|c|c|c|c|c|c|}
\hline Case number & $D_{s}(\mathrm{~mm})$ & $D_{B}(\mathrm{~mm})$ & $L(\mathrm{~m})$ & $s(\mathrm{~mm})$ & $Q_{p}(\mathrm{kN})$ & $Q_{m}(\mathrm{kN})$ & $a$ & $b$ \\
\hline 1 & 430 & 430 & 8 & 0.42 & 1321 & 1375 & 0.06 & 0.99 \\
\hline 2 & 600 & 750 & 9 & 0.76 & 3783 & 4600 & 0.74 & 0.94 \\
\hline 3 & 750 & 600 & 11 & 1.2 & 2705 & 3000 & 0.40 & 0.97 \\
\hline 4 & 360 & 350 & 7.8 & 35 & 1084 & 1050 & 7.98 & 0.61 \\
\hline 5 & 400 & 400 & 9.5 & 5.6 & 1202 & 1357 & 1.40 & 0.89 \\
\hline 6 & 400 & 400 & 9.5 & 10.1 & 1202 & 1380 & 1.45 & 0.92 \\
\hline 7 & 400 & 400 & 8 & 6 & 1131 & 1050 & 0.80 & 0.92 \\
\hline 8 & 400 & 400 & 9.5 & 5 & 1202 & 1225 & 1.97 & 0.84 \\
\hline 9 & 400 & 400 & 3 & 11 & 1178 & 840 & 3.70 & 0.72 \\
\hline 10 & 520 & 520 & 16.5 & 12.7 & 6754 & 5600 & 3.91 & 0.86 \\
\hline 11 & 430 & 430 & 11.5 & 3.41 & 1287 & 1250 & 0.75 & 0.94 \\
\hline 12 & 450 & 450 & 9 & 0.97 & 1145 & 1500 & 2.08 & 0.80 \\
\hline 13 & 400 & 400 & 10 & 50 & 940 & 970 & 3.88 & 0.74 \\
\hline 14 & 400 & 400 & 7 & 70 & 679 & 540 & 2.89 & 0.73 \\
\hline 15 & 500 & 500 & 7.8 & 75 & 1226 & 600 & 10.93 & 0.46 \\
\hline 16 & 500 & 500 & 10 & 77 & 1583 & 1175 & 5.29 & 0.59 \\
\hline 17 & 400 & 400 & 11 & 41 & 605 & 800 & 5.92 & 0.72 \\
\hline 18 & 400 & 400 & 9.2 & 57 & 472 & 480 & 7.87 & 0.58 \\
\hline 19 & 500 & 500 & 9.5 & 60 & 793 & 625 & 8.13 & 0.44 \\
\hline 20 & 500 & 500 & 11.8 & 62 & 1060 & 1025 & 10.46 & 0.51 \\
\hline 21 & 500 & 500 & 12.3 & 60 & 916 & 1160 & 4.29 & 0.70 \\
\hline 22 & 500 & 500 & 14.5 & 80 & 1132 & 1500 & 3.90 & 0.75 \\
\hline 23 & 305 & 305 & 13 & 40.3 & 2028 & 2010 & 8.44 & 0.50 \\
\hline 24 & 305 & 305 & 13 & 6.4 & 3051 & 6000 & 4.80 & 0.60 \\
\hline 25 & 305 & 305 & 13 & 97 & 2028 & 1200 & 1.30 & 0.53 \\
\hline 26 & 305 & 305 & 13 & 18.3 & 3051 & 4650 & 1.13 & 0.97 \\
\hline 27 & 520 & 760 & 12.2 & 50 & 2563 & 1690 & 2.97 & 0.83 \\
\hline 28 & 520 & 760 & 12.2 & 93 & 2478 & 1620 & 3.36 & 0.84 \\
\hline 29 & 520 & 760 & 12 & 26.5 & 2111 & 1650 & 5.36 & 0.80 \\
\hline 30 & 520 & 760 & 12 & 35 & 2451 & 2100 & 4.60 & 0.70 \\
\hline 31 & 520 & 760 & 15 & 23.3 & 2974 & 2680 & 8.80 & 0.85 \\
\hline 32 & 520 & 760 & 6 & 3.5 & 3644 & 3650 & 0.06 & 0.99 \\
\hline 33 & 520 & 760 & 8 & 5 & 3739 & 5600 & 0.74 & 0.94 \\
\hline
\end{tabular}

The classified results are shown in Tables 3 and 4. There are 21 and 38 pieces of data, of which bias factor is less than 0.25 in noncohesive soil and cohesive soil, respectively. The in situ uncertainties have little contribution to these data classified as "good data." There are 8 and 12 pieces of data, of which bias factor is larger than 0.25 but less than 0.50 in noncohesive soil and cohesive soil, respectively, considered as "general data." However, the bias factors of Case Number 15 in noncohesive soil and Cases Numbers 37, 68, and 69 in cohesive soil are $0.5187,0.5271,0.7315$, and 0.5203 , respectively. These data are classified as "bad data." These data can cause insecurity to engineering and should be discarded.

Log-normal distribution is used as the distribution of model factor, and the model factor statistics are presented in terms of the mean and coefficient of variation (COV). Based on equations (5) and (6), the updating model factors statistics are obtained in Table 5 for reliability analysis and resistance factor calculation. The coefficient of variation of updating data is minimum. The coefficient of variation for " general data" is maximum. In summary, the updating model factors are reliable enough to calculate the reliability index and resistance factor of bored piles.

According to reliability theory, the limit state equation of bored pile capacity is [16]:

$$
g\left(R, Q_{D}, Q_{L}\right)=R-Q_{D}-Q_{L},
$$

where $R$ is vertical pile capacity $(\mathrm{kN}) ; Q_{D}$ is dead load $(\mathrm{kN})$; and $Q_{L}$ is live load $(\mathrm{kN})$. Three methods are employed to calculate the reliability index.

3.1. First-Order Reliability Method. If the three parameters in equation (9) obey log-normal distribution, the calculation formula of reliability index can be written as [6]

$$
\beta=\frac{\ln \left(\left(\left(\lambda_{R} \mathrm{FOS}\left(\left(Q_{D} / Q_{L}\right)+1\right)\right) /\left(\lambda_{\mathrm{Q} D}\left(Q_{D} / Q_{L}\right)+\lambda_{\mathrm{QL}}\right)\right) \sqrt{\left(\left(1+\mathrm{COV}_{\mathrm{QD}}^{2}+\mathrm{COV}_{\mathrm{QL}}^{2}\right) /\left(1+\mathrm{COV}_{R}^{2}\right)\right)}\right)}{\sqrt{\ln \left(1+\mathrm{COV}_{R}^{2}\right)\left(1+\mathrm{COV}_{\mathrm{Q}_{D}}^{2}+\mathrm{COV}_{\mathrm{QL}}^{2}\right)}},
$$


TABLE 2: Load testing data of pile capacity in cohesive soil.

\begin{tabular}{|c|c|c|c|c|c|c|c|c|}
\hline Case number & $D_{s}(\mathrm{~mm})$ & $D_{B}(\mathrm{~mm})$ & $L(\mathrm{~m})$ & $s(\mathrm{~mm})$ & $Q_{p}(\mathrm{kN})$ & $Q_{m}(\mathrm{kN})$ & $a$ & $b$ \\
\hline 34 & 600 & 600 & 9 & 0.59 & 4807 & 4800 & 0.48 & 0.96 \\
\hline 35 & 600 & 600 & 11.5 & 2.7 & 6447 & 4100 & 2.87 & 0.82 \\
\hline 36 & 750 & 750 & 21.8 & 2.34 & 6521 & 7100 & 3.55 & 0.71 \\
\hline 37 & 350 & 350 & 17.3 & 0.18 & 1398 & 760 & 0.05 & 0.99 \\
\hline 38 & 610 & 610 & 6.5 & 21.19 & 2062 & 2300 & 3.40 & 0.80 \\
\hline 39 & 600 & 600 & 6.5 & 13.5 & 3280 & 3100 & 4.96 & 0.84 \\
\hline 40 & 600 & 800 & 24 & 12 & 2545 & 3360 & 12.43 & 0.64 \\
\hline 41 & 610 & 610 & 9 & 22.9 & 3040 & 2650 & 5.30 & 0.72 \\
\hline 42 & 610 & 610 & 7 & 1.65 & 2235 & 1800 & 1.08 & 0.90 \\
\hline 43 & 750 & 750 & 13 & 37 & 4179 & 3700 & 3.05 & 0.80 \\
\hline 44 & 450 & 450 & 9 & 1.79 & 3658 & 2930 & 1.76 & 0.88 \\
\hline 45 & 350 & 350 & 5 & 1.7 & 1196 & 1700 & 2.55 & 0.76 \\
\hline 46 & 500 & 500 & 6 & 1.7 & 2333 & 1900 & 2.85 & 0.76 \\
\hline 47 & 600 & 600 & 6 & 85.3 & 707 & 520 & 2.65 & 0.62 \\
\hline 48 & 450 & 450 & 6 & 20.3 & 1225 & 1175 & 0.82 & 0.94 \\
\hline 49 & 300 & 300 & 6 & 14.1 & 975 & 1080 & 1.19 & 0.86 \\
\hline 50 & 600 & 600 & 9.6 & 4.4 & 3223 & 3500 & 2.92 & 0.80 \\
\hline 51 & 400 & 400 & 8.7 & 2.9 & 1221 & 1240 & 0.82 & 0.93 \\
\hline 52 & 350 & 350 & 8.7 & 9 & 834 & 825 & 1.76 & 0.84 \\
\hline 53 & 410 & 410 & 11 & 0.95 & 1444 & 1450 & 1.45 & 0.87 \\
\hline 54 & 615 & 615 & 12 & 36 & 2375 & 3000 & 4.83 & 0.75 \\
\hline 55 & 615 & 615 & 12 & 35 & 1948 & 2450 & 3.92 & 0.74 \\
\hline 56 & 610 & 610 & 7 & 25.4 & 1184 & 1400 & 2.43 & 0.72 \\
\hline 57 & 610 & 610 & 1.5 & 17.8 & 462 & 510 & 1.00 & 0.93 \\
\hline 58 & 500 & 500 & 7.8 & 5.58 & 2392 & 3600 & 2.67 & 0.84 \\
\hline 59 & 430 & 430 & 6.5 & 4.49 & 907 & 1150 & 3.36 & 0.74 \\
\hline 60 & 450 & 600 & 15.5 & 4.19 & 1818 & 2310 & 2.98 & 0.82 \\
\hline 61 & 750 & 750 & 10.2 & 1.89 & 5869 & 8500 & 3.94 & 0.79 \\
\hline 62 & 450 & 450 & 8 & 45.53 & 1292 & 1230 & 8.40 & 0.50 \\
\hline 63 & 450 & 450 & 8 & 22.7 & 1292 & 1820 & 1.66 & 0.85 \\
\hline 64 & 450 & 450 & 8 & 3.93 & 2110 & 2580 & 1.52 & 0.89 \\
\hline 65 & 450 & 450 & 8 & 4.83 & 2110 & 2670 & 2.14 & 0.86 \\
\hline 66 & 450 & 450 & 8 & 4.0 & 2110 & 2790 & 2.39 & 0.84 \\
\hline 67 & 450 & 450 & 8 & 3.35 & 2110 & 2900 & 2.20 & 0.85 \\
\hline 68 & 450 & 450 & 8 & 2.85 & 2110 & 4200 & 3.86 & 0.76 \\
\hline 69 & 450 & 450 & 8 & 3.2 & 1602 & 2800 & 1.74 & 0.87 \\
\hline 70 & 450 & 750 & 4.5 & 2.96 & 8906 & 9600 & 4.22 & 0.76 \\
\hline 71 & 430 & 430 & 7 & 1.19 & 1156 & 1660 & 1.67 & 0.86 \\
\hline 72 & 550 & 550 & 6 & 6.57 & 2916 & 4800 & 1.46 & 0.90 \\
\hline 73 & 910 & 910 & 12 & 1.3 & 5088 & 7050 & 1.07 & 0.92 \\
\hline 74 & 910 & 910 & 9 & 1.8 & 5088 & 5900 & 0.99 & 0.93 \\
\hline 75 & 910 & 910 & 9 & 1.16 & 7648 & 9700 & 4.58 & 0.72 \\
\hline 76 & 910 & 910 & 9 & 0.68 & 4721 & 7000 & 1.78 & 0.86 \\
\hline 77 & 530 & 430 & 8 & 3.38 & 1955 & 1880 & 3.63 & 0.75 \\
\hline 78 & 600 & 600 & 14.9 & 2.13 & 4230 & 5430 & 3.48 & 0.79 \\
\hline 79 & 600 & 600 & 14.6 & 3.26 & 4196 & 3000 & 1.31 & 0.92 \\
\hline 80 & 750 & 750 & 15.4 & 2.35 & 6153 & 6250 & 1.93 & 0.89 \\
\hline 81 & 600 & 600 & 14.7 & 1.74 & 4207 & 4450 & 1.95 & 0.87 \\
\hline 82 & 750 & 750 & 15.7 & 1.95 & 10172 & 13000 & 5.37 & 0.75 \\
\hline 83 & 500 & 500 & 7.2 & 2.2 & 3294 & 3300 & 1.64 & 0.87 \\
\hline 84 & 750 & 750 & 7.2 & 1.6 & 6266 & 4810 & 0.88 & 0.93 \\
\hline 85 & 500 & 500 & 7.2 & 9.5 & 1901 & 2200 & 2.79 & 0.81 \\
\hline 86 & 750 & 750 & 7.2 & 7.2 & 3515 & 5300 & 4.03 & 0.77 \\
\hline
\end{tabular}

Note. $D_{s}$ is the pile shaft diameter; $D_{B}$ is the pile bottom diameter; $L$ is the pile length; $s$ is the final settlement of load tests; $a$ and $b$ are two hyperbolic curvefitting parameters.

where FOS is the factor of safety according to allowable stress design method; $\lambda_{\mathrm{QD}}$ and $\lambda_{\mathrm{QL}}$ are the partial factors of dead load and live load, respectively; $\mathrm{COV}_{\mathrm{OD}}$ and $\mathrm{COV}_{\mathrm{QL}}$ are the coefficients of variation of dead load and live load, respectively;
Table 5 gives the means and coefficients of variation for "updating data," "good data," and "general data," and the specifications give the load statistics; then the reliability index can be calculated using equation (10), which is described as $\beta_{\mathrm{MvF}}$. 

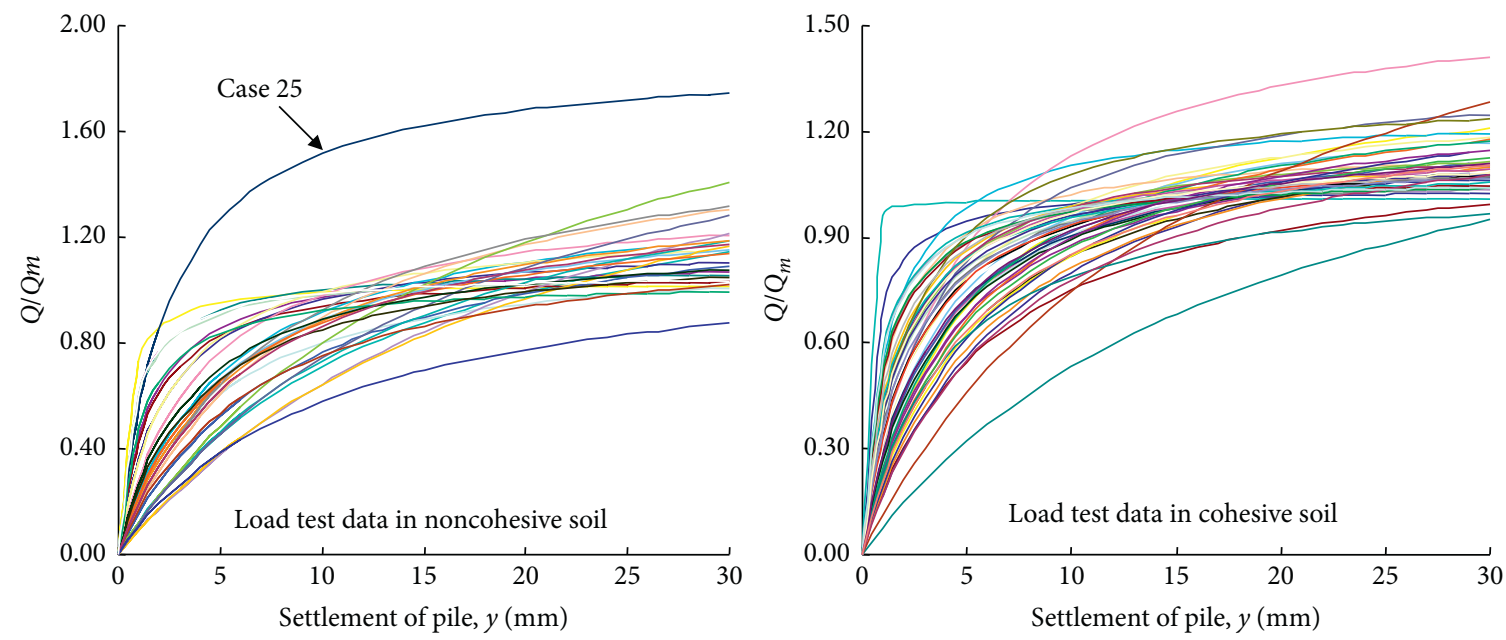

FIGURE 1: Normalized load-settlement curves of load test data.
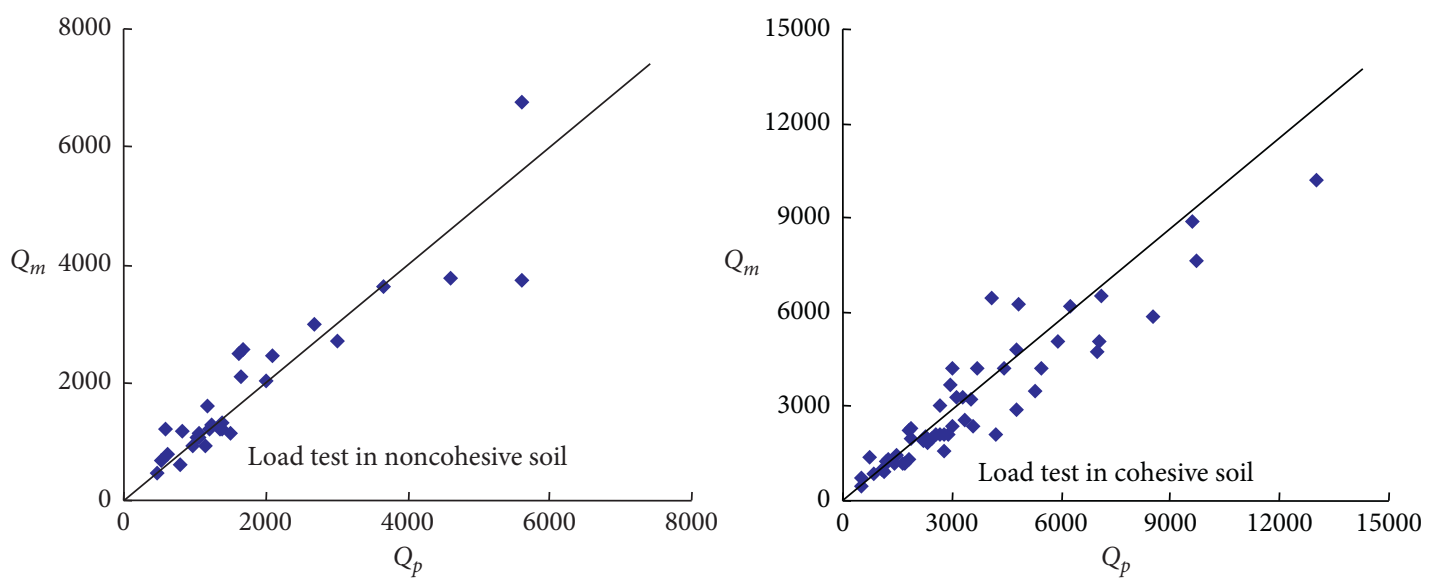

FIGURE 2: The scatter diagram of testing pile capacity and calculation pile capacity.

TABLE 3: Classified results of load test data in noncohesive soil.

\begin{tabular}{|c|c|c|c|c|c|c|c|c|}
\hline \multicolumn{6}{|c|}{ Good data } & \multicolumn{3}{|c|}{ General data } \\
\hline Case number & $\lambda_{R}$ & $\zeta_{i}$ & Case number & $\lambda_{R}$ & $\zeta_{i}$ & Case number & $\lambda_{R}$ & $\zeta_{i}$ \\
\hline 1 & 1.04 & 0.02 & 14 & 0.80 & 0.22 & 9 & 0.71 & 0.30 \\
\hline 2 & 1.22 & 0.20 & 18 & 1.02 & 0.00 & 12 & 1.31 & 0.29 \\
\hline 3 & 1.11 & 0.09 & 19 & 0.79 & 0.22 & 16 & 0.74 & 0.27 \\
\hline 4 & 0.97 & 0.05 & 20 & 0.97 & 0.05 & 17 & 1.32 & 0.30 \\
\hline 5 & 1.13 & 0.11 & 21 & 1.27 & 0.24 & 22 & 1.33 & 0.30 \\
\hline 6 & 1.15 & 0.13 & 23 & 0.99 & 0.03 & 27 & 0.66 & 0.35 \\
\hline 7 & 0.93 & 0.09 & 29 & 0.78 & 0.23 & 28 & 0.65 & 0.36 \\
\hline 8 & 1.02 & 0.00 & 30 & 0.86 & 0.16 & 33 & 1.50 & 0.47 \\
\hline 10 & 0.83 & 0.18 & 31 & 0.90 & 0.11 & - & - & - \\
\hline 11 & 0.97 & 0.04 & 32 & 1.00 & 0.00 & - & - & - \\
\hline 13 & 1.03 & 0.01 & - & - & - & - & - & - \\
\hline
\end{tabular}

3.2. Design Point Method. The limit-state function is linear at a point on the failure surface; its performance function is [6]

$$
g=\ln \left(\frac{\mathrm{FOS} \lambda_{R}\left(\left(Q_{D} / Q_{L}\right)+1\right)}{\lambda_{\mathrm{QD}}\left(Q_{D} / Q_{L}\right)+\lambda_{\mathrm{QL}}}\right)
$$

All the parameters in equation (11) have the same meanings as equation (10). The calculation can be carried out using MATLAB software, which is described as $\beta_{\mathrm{AF}}$.

3.3. Monte Carlo Simulation Method. Monte Carlo simulation method is an accuracy method to calculate reliability index, which is employed for comparison with the 
TABLE 4: Classified results of load test data in cohesive soil.

\begin{tabular}{|c|c|c|c|c|c|c|c|c|}
\hline \multicolumn{6}{|c|}{ Good data } & \multicolumn{3}{|c|}{ General data } \\
\hline Case number & $\lambda_{R}$ & $\zeta_{i}$ & Case number & $\lambda_{R}$ & $\zeta_{i}$ & Case number & $\lambda_{R}$ & $\zeta_{i}$ \\
\hline 34 & 1.00 & 0.13 & 60 & 1.27 & 0.11 & 35 & 0.64 & 0.45 \\
\hline 36 & 1.09 & 0.05 & 62 & 0.95 & 0.17 & 42 & 0.81 & 0.30 \\
\hline 38 & 1.12 & 0.03 & 63 & 1.41 & 0.23 & 44 & 0.80 & 0.30 \\
\hline 39 & 0.95 & 0.18 & 64 & 1.22 & 0.06 & 46 & 0.81 & 0.29 \\
\hline 40 & 1.32 & 0.15 & 65 & 1.27 & 0.10 & 47 & 0.74 & 0.36 \\
\hline 41 & 0.87 & 0.24 & 66 & 1.32 & 0.15 & 58 & 1.51 & 0.31 \\
\hline 43 & 0.89 & 0.23 & 67 & 1.37 & 0.20 & 61 & 1.45 & 0.26 \\
\hline 45 & 1.42 & 0.24 & 70 & 1.08 & 0.06 & 72 & 1.65 & 0.43 \\
\hline 48 & 0.96 & 0.17 & 71 & 1.44 & 0.25 & 76 & 1.48 & 0.29 \\
\hline 49 & 1.11 & 0.04 & 73 & 1.39 & 0.21 & 79 & 0.71 & 0.38 \\
\hline 50 & 1.09 & 0.06 & 74 & 1.16 & 0.01 & 84 & 0.77 & 0.33 \\
\hline 51 & 1.02 & 0.12 & 75 & 1.27 & 0.10 & 86 & 1.51 & 0.31 \\
\hline 52 & 0.99 & 0.14 & 77 & 0.96 & 0.16 & - & - & - \\
\hline 53 & 1.00 & 0.13 & 78 & 1.28 & 0.12 & - & - & - \\
\hline 54 & 1.26 & 0.10 & 80 & 1.02 & 0.12 & - & - & - \\
\hline 55 & 1.26 & 0.09 & 81 & 1.06 & 0.08 & - & - & - \\
\hline 56 & 1.18 & 0.03 & 82 & 1.29 & 0.11 & - & - & - \\
\hline 57 & 1.10 & 0.04 & 83 & 1.00 & 0.13 & - & - & - \\
\hline 59 & 1.27 & 0.10 & 85 & 1.16 & 0.01 & - & - & - \\
\hline
\end{tabular}

TABle 5: The updating model factor for pile capacity.

\begin{tabular}{lcccccccc}
\hline & \multicolumn{3}{c}{ All data } & \multicolumn{2}{c}{ Model factor } & \multicolumn{2}{c}{ Good data } & \multicolumn{2}{c}{ Updating data } \\
Soil type & Mean & COV & Mean & COV & Mean & COV & Mean & COV \\
\hline Noncohesive soil & 1.000 & 0.217 & 0.990 & 0.138 & 1.028 & 0.357 & 0.987 & 0.129 \\
Cohesive soil & 1.134 & 0.210 & 1.153 & 0.140 & 1.073 & 0.372 & 1.134 & 0.132 \\
\hline
\end{tabular}

accuracy of other calculation methods. Its performance function is

$$
g=\operatorname{FOS} \lambda_{R}\left(\frac{Q_{D}}{Q_{L}}+1\right)-\left(\lambda_{\mathrm{QD}} \frac{Q_{D}}{Q_{L}}+\lambda_{\mathrm{QL}}\right) .
$$

The calculation can be carried out using MATLAB software; the times of simulation are 10 million, described as $\beta_{\text {MCS. }}$.

The values of $\lambda_{\mathrm{QD}}, \lambda_{\mathrm{QL}}, \mathrm{COV}_{\mathrm{QD}}$, and $\mathrm{COV}_{\mathrm{QL}}$ can be obtained according to LRFD for Bridge Design Specification. 3.69 is selected as the value of $\left(Q_{D} / Q_{L}\right)$ [27].

Figures 3 and 4 show the calculation results of reliability index. The results indicate that the deviation of reliability index for "good data" and "general data" is larger than 1.0, which is caused by the quality of data. However, the reliability index of "good data" is near to the reliability index of "updating data." In addition, reliability index is sensitive to soil type. Reliability index in cohesive soil is larger than that in noncohesive soil. is [6]

The formula of load and resistance factor design method

$$
\phi R_{n} \geq \eta \sum \gamma_{i} Q_{i}
$$

where $R_{n}$ is standard value of resistance $(\mathrm{kN}) ; Q_{i}$ is standard value of load $(\mathrm{kN}) ; \phi$ is the resistance factor; and $\gamma_{i}$ is load factor.

Reliability analysis is the bias of resistance factor calculation. Load and resistance factor design method proposes the calculation formula shown in equation (14) based on first-order reliability method [6]:

$$
\phi=\frac{\lambda_{R}\left(\gamma_{\mathrm{QD}}\left(Q_{D} / Q_{L}\right)+\gamma_{\mathrm{QL}}\right) \sqrt{\left(\left(1+C O V_{\mathrm{QD}}^{2}+C O V_{\mathrm{QL}}^{2}\right) /\left(1+C O V_{R}^{2}\right)\right)}}{\left(\lambda_{\mathrm{QD}}\left(Q_{D} / Q_{L}\right)+\lambda_{\mathrm{QL}}\right) \exp \left(\beta_{T} \sqrt{\left(\left(1+C O V_{\mathrm{QD}}^{2}+C O V_{\mathrm{QL}}^{2}\right) /\left(1+C O V_{R}^{2}\right)\right)}\right)},
$$

where $\beta_{T}$ is target reliability index of piles. 1.75 and 1.08 are selected as the values of $\gamma_{Q_{L}}$ and $\gamma_{Q_{D}}$ according to LRFD for
Bridge Design Specification. The resistance factor is described as $\phi_{\mathrm{MvF}}$ according to equation (14). 


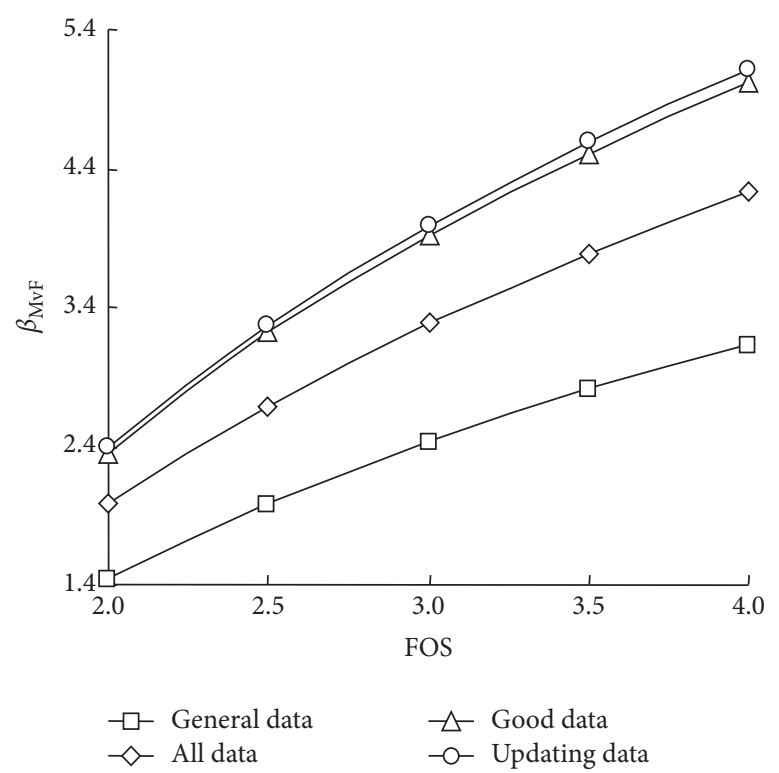

(a)

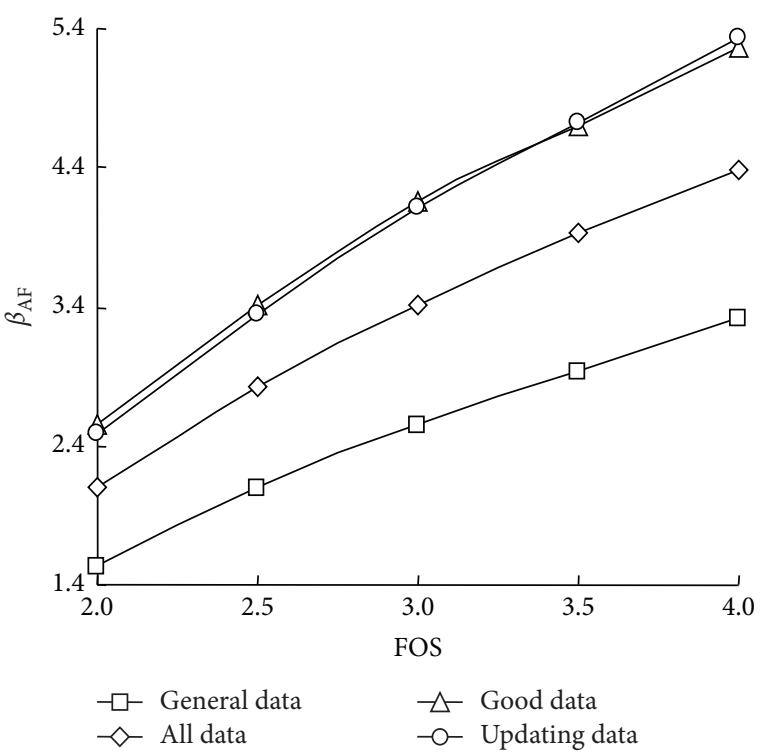

(b)

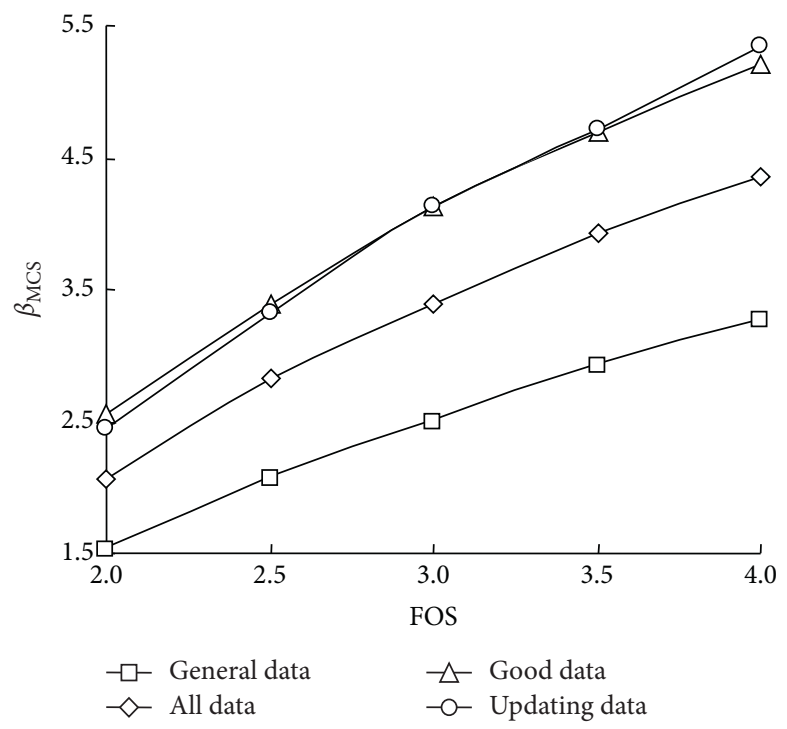

(c)

Figure 3: Reliability index in noncohesive soil. (a) First-order reliability method. (b) Design point method. (c) Monte Carlo simulation method.

If the reliability index is calculated using equation 11), the limit state equation for resistance factor calculation is

$$
g_{\varphi}=\ln \left(\frac{\lambda_{R}\left(\gamma_{\mathrm{QD}}\left(Q_{D} / Q_{L}\right)+\gamma_{\mathrm{QL}}\right)}{\phi\left(\lambda_{\mathrm{QD}}\left(Q_{D} / Q_{L}\right)+\lambda_{\mathrm{QL}}\right)}\right)=0 .
$$

The resistance factor is described as $\phi_{\mathrm{AF}}$ according to equation (15).

If the reliability index is calculated using equation (12), the limit state equation for resistance factor calculation is

$$
g=\left(\frac{\lambda_{R}}{\phi}\right)\left(\gamma_{\mathrm{QD}} \frac{Q_{D}}{Q_{L}}+\gamma_{\mathrm{QL}}\right)-\left(\lambda_{\mathrm{QD}} \frac{Q_{D}}{Q_{L}}+\lambda_{\mathrm{QL}}\right)=0 .
$$

The resistance factor is described as $\phi_{\mathrm{MCS}}$ according to equation (16).
2.0, 2.5, and 3.0 are selected as the target reliability index. Based on equations (14)-(16), the calculation results of resistance factor are shown in Table 6.

The quality of data has distinct contribution to resistance factor of bored piles. The accuracies of design point method and Monte Carlo simulation method are satisfactory, which can be considered as the criterion to verify the accuracy of proposed method. The results based on two methods are larger than the results based on first-order reliability method, and the difference are $6.9 \%$ and $18.3 \%$, respectively. Meanwhile, the difference between the two methods is near 0 . The accuracies based on "good data" and "updating data" are better than the accuracies based on "general data" and "all data."

In summary, Table 7 shows the recommended values of resistance factors. However, the reliability theory of pile 


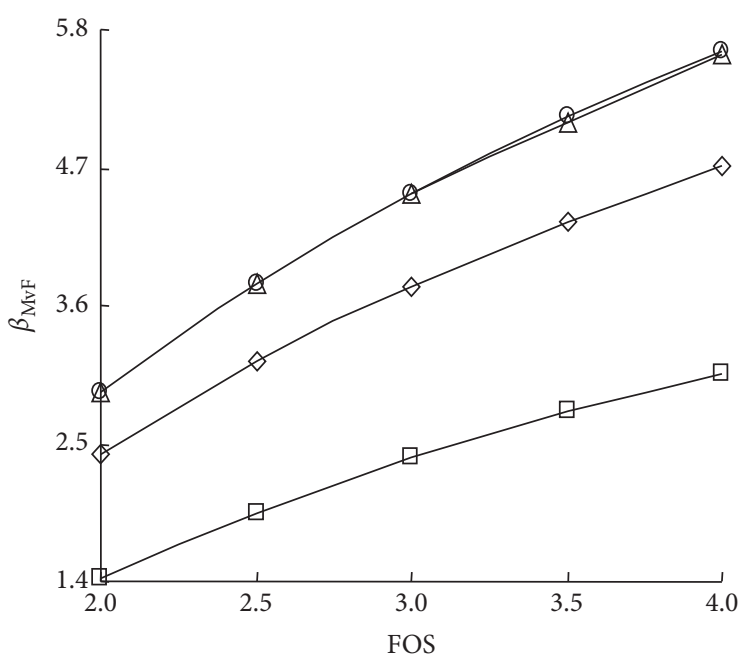

$\square$ General data $\diamond$ All data

$$
\begin{aligned}
& \triangle \text { Good data } \\
& \bigcirc \text { Updating data }
\end{aligned}
$$

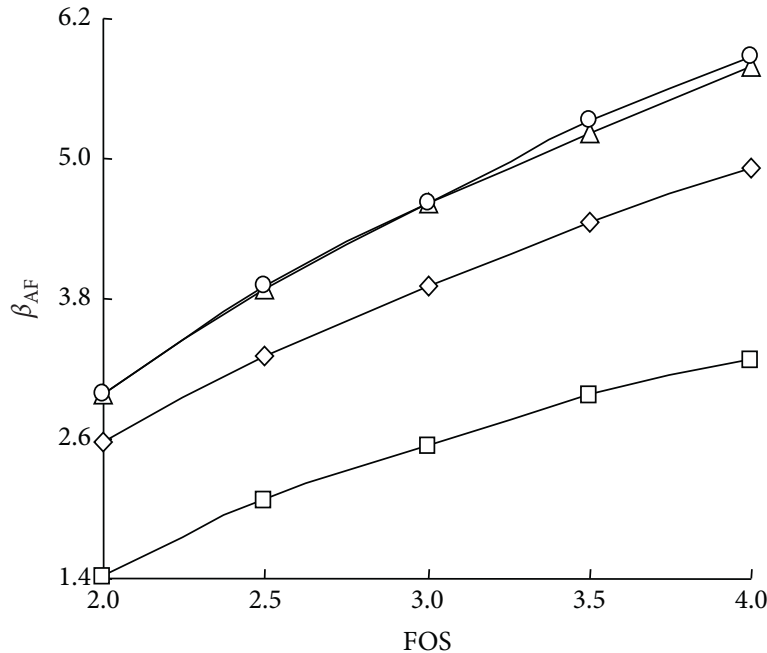

$\neg-$ General data $\quad-\neg$ Good data $\checkmark$ All data $\triangle \leftarrow$ Good data
$-\bigcirc-$ Updating dat

(b)

b)

(a)

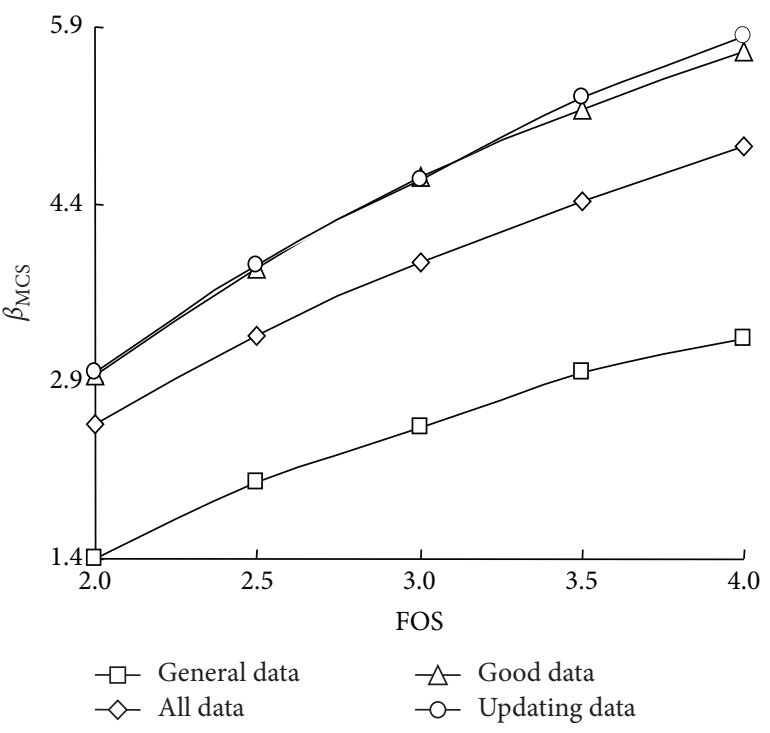

(c)

Figure 4: Reliability index in cohesive soil. (a) First-order reliability method. (b) Design point method. (c) Monte Carlo simulation method.

\begin{tabular}{|c|c|c|c|c|c|c|}
\hline \multirow{2}{*}{ Target reliability, $\beta_{T}$} & \multicolumn{3}{|c|}{ Noncohesive soil } & \multicolumn{3}{|c|}{ Cohesive soil } \\
\hline & $\phi_{\mathrm{MvF}}$ & $\phi_{\mathrm{AF}}$ & $\phi_{\mathrm{MCS}}$ & $\phi_{\mathrm{MvF}}$ & $\phi_{\mathrm{AF}}$ & $\phi_{\mathrm{MCS}}$ \\
\hline \multicolumn{7}{|l|}{ All data } \\
\hline 2.0 & 0.440 & 0.452 & 0.450 & 0.461 & 0.476 & 0.475 \\
\hline 2.5 & 0.375 & 0.389 & 0.389 & 0.387 & 0.396 & 0.394 \\
\hline 3.0 & 0.336 & 0.354 & 0.353 & 0.344 & 0.362 & 0.360 \\
\hline \multicolumn{7}{|l|}{ General data } \\
\hline 2.0 & 0.437 & 0.446 & 0.445 & 0.443 & 0.450 & 0.450 \\
\hline 2.5 & 0.371 & 0.382 & 0.380 & 0.375 & 0.385 & 0.384 \\
\hline 3.0 & 0.333 & 0.350 & 0.350 & 0.335 & 0.347 & 0.345 \\
\hline \multicolumn{7}{|l|}{ Good data } \\
\hline 2.0 & 0.440 & 0.446 & 0.445 & 0.467 & 0.475 & 0.474 \\
\hline 2.5 & 0.376 & 0.385 & 0.385 & 0.391 & 0.399 & 0.399 \\
\hline 3.0 & 0.337 & 0.348 & 0.347 & 0.346 & 0.356 & 0.354 \\
\hline
\end{tabular}

TABLE 6: Calculation results of resistance factor. 
TABle 6: Continued.

\begin{tabular}{lcccrr}
\hline Target reliability, $\beta_{T}$ & \multicolumn{3}{c}{ Noncohesive soil } & \multicolumn{2}{c}{ Cohesive soil } \\
& $\phi_{\mathrm{MvF}}$ & $\phi_{\mathrm{AF}}$ & $\phi_{\mathrm{MCS}}$ & $\phi_{\mathrm{MvF}}$ & $\phi_{\mathrm{AF}}$ \\
\hline Updating data & & & & 0.463 & 0.472 \\
2.0 & 0.440 & 0.449 & 0.448 & 0.390 & 0.400 \\
2.5 & 0.376 & 0.385 & 0.384 & 0.345 & 0.358 \\
3.0 & 0.337 & 0.348 & 0.348 & 0.300 \\
\hline
\end{tabular}

TABLE 7: Recommended values of resistance factors.

\begin{tabular}{lcc}
\hline$\beta_{T}$ & Noncohesive soil & Cohesive soil \\
\hline 2.0 & 0.456 & 0.473 \\
2.5 & 0.386 & 0.400 \\
3.0 & 0.347 & 0.356 \\
\hline
\end{tabular}

foundation is not perfect enough to be applied in engineering fact. The recommended values are proposed only according to the calculation results and American LRFD for Bridge Design Specification. Its application in engineering field needs to be further studied.

\section{Conclusions}

From this study, some conclusions are presented:

(1) The proposed method incorporating probability theory and Bayesian method can not only classify the in situ data but also overcome the deficiency caused by small sample for accuracy data.

(2) Data classification has significant contribution to reliability index and resistance factor. The results according to "good data" and "updating data" are larger than the results according to "general data" and "all data." Meanwhile the difference of results using two types of data is near 0. Therefore, "good data" and "updating data" can be used as the basis of resistance factor calculation.

(3) Reliability index and resistance factor are sensitive to the type of soil, and the calculation results in cohesive soil are larger than the results in noncohesive soil.

(4) The recommended values are proposed only according to the calculation results and American LRFD for Bridge Design Specification. Its application in engineering fact needs to be further studied. However, the proposed method can be used to update other geotechnical data.

\section{Data Availability}

The data used to support the findings of this study are available from the corresponding author upon request.

\section{Conflicts of Interest}

The authors declare that there are no conflicts of interest regarding the publication of this paper.

\section{Acknowledgments}

The authors express their gratitude to the National Natural Science Foundation of China (no. 51978247) and Key Science and Technology Projects of Henan Province (no. 202102310242).

\section{References}

[1] M. Dithinde, K. K. Phoon, D. M. Wet, and J. V. Retief, "Characterization of model uncertainty in the static pile design formula," Journal of Geotechnical and Geoenvironmental Engineering, vol. 137, no. 1, pp. 70-85, 2010.

[2] L. M. Zhang, D. Q. Li, and W. H. Tang, "Reliability of bored pile foundations considering bias in failure criteria," Canadian Geotechnical Journal, vol. 42, no. 4, pp. 1086-1093, 2005.

[3] W. Y. Lam, "Reliability of bored piles with defects," Final Year Report, Hong Kong University of Science and Technology, Hong Kong, 2004.

[4] N. F. Ismael, "Axial load tests on bored piles and pile groups in cemented sands," Journal of Geotechnical and Geoenvirmental Engineering, vol. 127, no. 9, pp. 766-773, 2001.

[5] D. Q. Li, W. H. Tang, and L. M. Zhang, "Updating occurrence probability and size of defect for bored piles," Structural Safety, vol. 30, no. 2, pp. 130-143, 2008.

[6] AASHTO, LRFD for Bridge Design Specifications, American Association of State Highway and Transportation Officials, Washington, WA, USA, 8th edition, 2017.

[7] C. Tang and K. K. Phoon, "Characterization of model uncertainty in predicting axial resistance of piles driven into clay," Canadian Geotechnical Journal, vol. 56, no. 8, pp. 1098-1118, 2019.

[8] C. Tang and K. K. Phoon, "Evaluation of model uncertainties in reliability based design of steel H-piles in axial compression," Canadian Geotechnical Journal, vol. 55, no. 11, pp. 1513-1532, 2018.

[9] D. Kim and J. Lee, "Resistance factor contour plot analyses of load and resistance factor design of axially-loaded driven piles in clays," Computers and Geotechnics, vol. 44, pp. 9-19, 2012.

[10] K. N. Flynn and B. A. Mccabe, "Shaft resistance of driven castin-situ piles in sand," Canadian Geotechnical Journal, vol. 53, no. 1, pp. 49-59, 2016.

[11] W. Gong, C. H. Juang, S. Khoshnevisan, and K.-K. Phoon, " $R$ LRFD: load and resistance factor design considering robustness," Computers and Geotechnics, vol. 74, pp. 74-87, 2016.

[12] K. Kwak, K. J. Kim, J. Huh, J. H. Lee, and J. H. Parka, "Reliability-based calibration of resistance factors for static bearing capacity of driven steel pipe piles," Canadian Geotechnical Journal, Forum, vol. 47, no. 5, pp. 528-538, 2010.

[13] J. H. Park, J. Huh, K. J. Kim et al., "Resistance factors calibration and its application using static load test data for driven 
steel pipe piles," KSCE Journal of Civil Engineering, vol. 17, no. 5, pp. 929-938, 2013.

[14] D. W. Kim, M. Y. Chung, and K. Kwak, "Resistance factor calculations for LRFD of axially loaded driven piles in sands," KSCEJournal of Civil Engineering, vol. 15, no. 7, pp. 11851196, 2011.

[15] K. W. Ng and S. Sritharan, "A procedure for incorporating setup into load and resistance factor design of driven piles," Acta Geotechnica, vol. 11, no. 2, pp. 347-358, 2016.

[16] J. J. Zheng, Z. J. Xu, Y. Liu, and X. Y. Bian, "Bayesian optimization for resistance factor of piles," Chinese Journal of Geotechnical Engineering, vol. 34, no. 5, pp. 1716-1721, 2012.

[17] CEN EN 1997-1., Geotechnical Design-Part 1: General Rules, European Committee for Standardization (CEN), Brussels, Belgium, 2004.

[18] A. L. Jones, S. L. Keamer, and P. Arduino, "Estimation of uncertainty in geotechnical properties for performance earthquake engineering," PEER Report 2002/16, University of California, Berkeley, CA, USA, 2002.

[19] F. K. Kulhawy and C. H. Trutmann, "Estimation of in-situ test uncertainty," Geotechnical Special Publication, vol. 58, pp. 269-286, ACSE, Reston, VA, USA, 1996.

[20] S. Lacsse and F. Nadim, "Model uncertainty in pile axial capacity calculations," in Proceeding of 28th Offshore Technology Annual Conference, Houston, TX, USA, 1996.

[21] G. G. Meyerhof, "Bearing capacity and settlement of pile foundations," Journal of the Geotechnical Engineering Division, vol. 102, no. 3, pp. 197-228, 1976.

[22] K. K. Phoon and F. H. Kulhawy, "Characterization of geotechnical variability," Canadian Geotechnical Journal, vol. 36, no. 4, pp. 612-624, 1999.

[23] K. K. Phoon, Reliability-Based Design in Geotechnical Engineering: Computations and Applications, Taylor \& Francis, London, UK, 2008.

[24] M. William, Introduction to Bayesian Statistics, Wiley \& Sons, New York, NY, USA, 2nd edition, 2007.

[25] K. K. Phoon, Reliability-based design of foundations for transmission line structures, Ph.D. dissertation, Cornell University, New York, NY, USA, 1995.

[26] A. H. S. Ang and W. H. Tang, Probability Concepts in Engineering: Emphasis on Applications to Civil and Environmental Engineering, John Wiley \& Sons, New York, NY, USA, 2nd edition, 2006.

[27] R. M. Barker, J. M. Duncan, K. B. Rojiani, P. S. K. Ooi, C. K. Tan, and S. G. Kim, "Load factor design criteria for highway structure foundations," Final Report NCHRP Project 24-4, Virginia Polytechnic Institute and State University, Blacksburg, VA, USA, 1991. 